\title{
Endoscopic Ultrasound-Guided Fine Needle Aspiration Cytology of Gastrointestinal Tract Tumors and Related Organs: Predictive Factors for Accurate Cytopathological Diagnosis
}

\author{
Mahmoud Gamal Ameen1*, Moemen Mostafa Hafez ${ }^{2}$, Eatemad Helmy Yassen², Wael Ahmed Abbas ${ }^{3}$ \\ ${ }^{1}$ Department of Oncological Pathology, South Egypt Cancer Institute, Assiut University, Assiut, Egypt \\ ${ }^{2}$ Department of Pathology, Faculty of Medicine, Assiut University, Assiut, Egypt \\ ${ }^{3}$ Department of Internal Medicine, Gastroenterology Unit, Faculty of Medicine, Assiut University, Assiut, Egypt \\ Email:^mahmoudameengamal@aun.edu.eg, ${ }^{\star}$ mahmoudameengamal@yahoo.com
}

How to cite this paper: Ameen, M.G., Hafez, M.M., Yassen, E.H. and Abbas, W.A. (2020) Endoscopic Ultrasound-Guided Fine Needle Aspiration Cytology of Gastrointestinal Tract Tumors and Related Organs: Predictive Factors for Accurate Cytopathological Diagnosis. Open Journal of Pathology, 10, 35-50.

https://doi.org/10.4236/ojpathology.2020.1 $\underline{01004}$

Received: December 1, 2019

Accepted: December 30, 2019

Published: January 3, 2020

Copyright $\odot 2020$ by author(s) and Scientific Research Publishing Inc. This work is licensed under the Creative Commons Attribution International License (CC BY 4.0).

http://creativecommons.org/licenses/by/4.0/

\section{(c) (i) Open Access}

\begin{abstract}
Background: Endoscopic ultrasonography (EUS) is well-established, highly accurate clinical diagnostic test for detection and staging of gastrointestinal tract lesions and related organs. The addition of endoscopic guided fine needle aspiration cytology (EUS-FNAC) has improved the performance characteristics of EUS. Aim: Evaluate the validity of EUS-FNAC in diagnosis of gastrointestinal tract lesions and related organs and assess predictive factors for an accurate EUS-FNAC diagnosis. Methods: Our study included cytological sampling from one hundred sixty-six lesions obtained from gastrointestinal tract and related organs. Factors affecting EUS-FNA accuracy were analyzed. The histopathological results or clinical follow-up were used as the gold standard method. Results: Samples were obtained from: pancreatic masses (n $=80)$, gastric masses $(n=34)$, lymph nodes $(n=22)$, hepatobiliary masses $(n$ $=18)$ and rectal masses $(n=2)$. Statistical analysis of sensitivity, specificity, Positive Predictive Value, Negative Predictive Value, and diagnostic accuracy of EUS alone was $80.4 \%, 51.6 \%, 75.8 \%, 76.2 \%$ and $75.9 \%$ respectively. The sensitivity, specificity, positive predictive value and negative predictive value of EUS-FNAC are $78.8 \%, 96.8 \%, 97.6 \%$ and $73.2 \%$ respectively. Addition of FNAC to EUS improved diagnostic accuracy to $85.5 \%$. Positive statistical association was present between cytological adequacy and adequate cell block preparations, larger lesion size, presence of rapid on site evaluation (ROSE) and obtaining at least two passes from target lesion. Conclusions: EUS is valuable diagnostic and cost effective tool for gastrointestinal tract lesions and related organs when combined with FNAC.
\end{abstract}




\section{Keywords}

Endoscopic Ultrasound-Guided Fine Needle Aspiration (EUS-FNA), Diagnostic Accuracy, Cell-Block Examination, Rapid On-Site Evaluation

\section{Introduction}

Endoscopic ultrasonography (EUS) means the use of endoscope to introduce high-frequency ultrasound probes in the upper or lower part of the gastrointestinal tract to visualize its wall and adjacent structures [1]. It is well-established, highly accurate clinical diagnostic test for the detection and staging of gastrointestinal tract lesions and related organs [2]. The addition of endoscopic guided fine needle aspiration cytology (EUS-FNAC) has improved the performance characteristics of EUS. European Society of Gastrointestinal Endoscopy (ESGE) published the guidelines for EUS FNAC sampling, with technical prerequisites for maximizing the diagnostic yield of this procedure [3]. EUS carries many advantages over other procedures. It allows the visualization, identification, and characterization of the extent of lesions of the gastrointestinal tract and adjacent structures [4]. Also, it allows sampling of submucosal and deep seated lesions that were previously accessible only by laparotomy. EUS-FNAC procedure with experienced hands can replace many other invasive and risky diagnostic procedures, such as mediastinoscopy, diagnostic laparoscopy and even laparotomy or thoracotomy. So, it is a less invasive technique than open biopsy and provides a cost-effective modality for the diagnosis and management of gastrointestinal lesions [5]. Moreover, unnecessary surgical interventions in advanced pancreatic cancer can be avoided with proper locoregional staging of pancreatic cancer being an integral part of the diagnosis and staging of pancreatic tumors with overall accuracy of EUS is superior to computed tomography (CT) scan and magnetic resonance imaging (MRI) for detecting pancreatic lesions [6].

Endosonographers introduce EUS probe to identify the lesion of interest and its characteristics and make it at the center of image. Elastography can be used to identify lesion nature and determine most proper site for FNAC sampling from target lesion. Elastography works by determining the elasticity of tissue within the scanned area and compare it with the surrounding tissue [7]. The elasticity of tissue was translated into a color signal. These colors include blue, green, and yellow/red that indicate tissue nature. Hard, intermediate, and soft tissues were reflected into blue, green, and yellow/red respectively [8].

Elastography output pattern of target lesion depends on dominant colors and their distribution within the lesions that are translated into scores as demonstrated in Table 1 [9].

Endosonographers can obtain material from target lesion by different techniques for maximal cytological sufficiency. First one is standard suction method performed by suction syringe with pressure volume that ranges from $5-10 \mathrm{ml}$ to 
Table 1. Five score classification system for endoscopic ultrasound elastography [9].

\begin{tabular}{ccc}
\hline Score & Color pattern & Stiffness \\
\hline 1 & Green & Soft homogeneity \\
2 & Green, yellow and red & Soft heterogeneity \\
3 & Mostly blue with minimal heterogeneity & Hard \\
4 & Central green hypoechoic region and blue tissue outer layer & Hard \\
5 & Blue lesions with heterogeneity due to necrosis & Hard \\
\hline
\end{tabular}

provide optimal cellularity. Also needle movement back and forth by 10 to 20 times under EUS guidance was combined with suction to improve cellularity. Second one slow pull suction (capillary technique) in which material is obtained by the action of capillary pressure within the needle with no negative pressure applied at all [5]. Third method is Door Knocking technique that obtain cytological material by puncturing target lesion using maximal quick needle progression within it, for 15 - 20 times, without advancement of needle outside lesion boundaries [10].

Fanning by needle is a manner by which cytological material can be improved. It is used to sample different areas of lesion at same pass and by using same needle. The fanning range within lesion was between 2 - 4 fans according to its size [11].

ROSE is ability to obtain cytological material from target lesion under direct visualization by using microscope at the time of EUS-FNAC procedure. It offers an opportunity for prompt and accurate diagnosis and improves the diagnostic yield, decreasing unsatisfactory samples, patient's risk of complication or need for additional passes, and consequently the procedure time [12].

Cell block is a way by which cytological material from target lesion can be converted into pellet embedded in paraffin block that is used for better preservation of cell architecture, stained with hematoxylin and eosin (H\&E) and subjected to immunohistochemistry (IHC) or molecular analyses. It is prepared by adding the aspirated material to mixture of $8 \mathrm{ml}$ of absolute alcohol and $2 \mathrm{ml}$ of $10 \%$ diluted $4 \%$ formalin [13].

The present study aimed to evaluate validity of EUS-FNAC in diagnosis of gastrointestinal tract lesions and related organs and assess the predictive factors for accurate EUS-FNAC diagnosis.

\section{Patients and Methods}

One hundred sixty-six patients between January 2015 to August 2019 in a tertiary level referral medical center with collaboration between Oncological Pathology Department at South Egypt Cancer Institute and Gastroenterology Department at El-Rajhy University Hospital at Assuit University in Egypt were subjected for EUS-FNAC. They are presented with obstructive jaundice, persistent abdominal pain or loss of weight but persistent abdominal pain was the most frequent complaint. The study was approved by the ethical research committee of Assuit University Hospitals and a written informed consent was ob- 
tained from all patients.

\subsection{Evaluation of Selected Patients}

Patient selection based on the presence of normal endoscopic findings in spite of persistent complaint for example; persistent abdominal pain or patients have pancreatic lesion, gastrointestinal tract-related organs mass or biliary structuring mass on radiological study. Also patients with known gastrointestinal tract or related organ malignancy were selected for staging by FNAC sampling of nearby lymph nodes. The procedure including final diagnostic cytopathologic report costs nearly $600-700 \$$.

The exclusion criteria of our study include pregnant female, patient with any coagulation disorder (PLT $<50,000 / \mathrm{mm}^{3}$, INR (international normalized ratio) $>$ 1.5), patients refused to give an informed legal consent for the protocol of the study, severe co-existed cardiopulmonary and/or renal disease, inaccessible lesion and the presences of intervening blood vessels that hinder lesion sampling.

\subsection{Technique}

The procedure was performed with the patient under sedation using propofol 1\% (manufactured by Baxter, USA). Endosonographic examination was carried out utilizing the forward oblique viewing Pentax linear echoendoscope (EG-3870 UTK, Pentax, Japan) and ultrasound (Hitachi Prius, Tokyo) had been used. Once the lesion was evaluated by EUS, the echoendoscopist would select the shortest pathway for FNAC that was done by targeting of the lesion at the center of EUS image, closest to the transducer and avoiding intervening vessels by color Doppler imaging. Approach for acquiring tissue was trans esophageal, trans gastric, transrectal or trans duodenal depending on the site of the lesion. The needle size used was a 19, 22 and 25 gaugea EUS-FNA needle (Echo tip ultra-3, cook medical, USA) according to site and nature of lesion.

After penetrating the lesion by the proper needle, different techniques are used to obtain sample from target lesion that includes standard Suction method, Slow Suction method and Door Knocking technique.

Different pressure volumes are applied to dissecting needle to obtain proper cytological sample and includes $0 \mathrm{cc}, 5 \mathrm{cc}$ and $10 \mathrm{cc}$ pressure volume. Fanning within lesion was performed and range between $2-4$ fans.

\subsection{Cytological Evaluation}

ROSE was performed for 86 (51.8\%) cases and used to confirm adequacy before subsequent punctures in the same patient.

Cases in which ROSE was present, half of slides evaluated were stained by Diff-Quick and the other half were immediately fixed in 95\% ethyl alcohol for a minimum of 15 minutes for later staining with $\mathrm{H} \& \mathrm{E}$ stain.

Cases in which ROSE was not present, all smeared slides were immediately fixed in 95\% ethyl alcohol for a minimum of 15 minutes for later staining with $\mathrm{H}$ 
\& E stain.

Cell block preparation and processing for ROSE group was performed when on site evaluation showed undifferentiated neoplasm and for lesions with borderline cellularity. While group without ROSE, the endosonographers submit part of aspirated material in formalin performed cell block for hardly accessible or submucosal lesions. Cell block was performed in 54 (32.5\%) cases.

Adequate EUS-FNA cytology samples, of gastrointestinal lesions and related organs with exception of pancreatic lesions were interpreted as negative, atypical cells, suspicious of malignancy and malignant [14].

EUS-FNA cytology samples of pancreatic lesions were reported according to Papanicolaou Society for assessment of cytological sampling of pancreatobiliary system [15].

Inadequate EUS-FNA cytology samples were interpreted as unsatisfactory for diagnosis and reported as false negative results [16].

\subsection{Statistical Analysis}

The sensitivity, specificity, diagnostic accuracy, positive predictive value (PPV) and negative predictive value (NPV) of EUS-FNAC, EUS and Elastography are evaluated in relation to gold standard procedure.

The gold standard procedure includes final pathological results for patients undergoing surgical interference or biopsy. While patients did not undergo surgical interference or biopsy, their clinical course based on follow-up over a period of at least 6 - 12 months, both clinically and radiologically, was used as the gold standard method. If patient developed clinical or radiographic evidence of local or distant metastasis based on clinical records were considered as positive for malignancy [17] [18]. If patient lacked disease progression, his lesion was defined as negative for malignancy [14].

Chi-square test was used to compare the difference in distribution of frequencies among different groups. For continuous variables; independent t-test analysis was carried out to compare the means of normally distributed data, while Mann-Whitney $U$ test was calculated to test the median differences of the data that do not follow normal distribution. ANOVA test was calculated to test the mean differences of the data that follow normal distribution. A significant $p$ value was considered when it is equal or less than 0.05 .

\section{Results}

A total of one hundred sixty-six patients underwent EUS-FNAC.

Patient sociodemographic and clinical characteristics are shown in Table 2.

Sufficient cytological diagnosis was achieved in 136 (81.9\%) cases while cytological insufficiency was detected in 30 (18.1\%) cases.

Final diagnostic results for each procedure used and for gold standard procedure used are shown in Table 3.

Figures 1-5 showed cytological, EUS and Elastography characteristics of various sampled lesions. 
Table 2. Procedure and sociodemographic characteristics.

\begin{tabular}{|c|c|c|}
\hline Variable & Category & $\mathrm{n}=166$ \\
\hline Mean age (range) (years) & $52.87 \pm 13.9$ & \\
\hline Sex (male/female) & $92 / 74$ & \\
\hline \multirow[t]{4}{*}{ Endoscopic Approach } & Trans-gastric & $96(57.8 \%)$ \\
\hline & Trans-duodenal & $54(32.6 \%)$ \\
\hline & Trans-esophageal & $14(8.4 \%)$ \\
\hline & Trans-rectal & $2(1.2 \%)$ \\
\hline \multirow[t]{4}{*}{ Number of Fanning } & No & $60(36.1 \%)$ \\
\hline & Two & $56(33.7 \%)$ \\
\hline & Three & $28(16.9 \%)$ \\
\hline & Four & $22(13.3 \%)$ \\
\hline \multirow[t]{2}{*}{ Lesion Size/cm } & Mean \pm SD & $5.01 \pm 1.0$ \\
\hline & Median (Range) & $2.8(0.9-50)$ \\
\hline \multirow[t]{3}{*}{ Technique Used } & Door Knocking & $74(44.6 \%)$ \\
\hline & Slow Suction & $30(18.1 \%)$ \\
\hline & Standard Suction & $62(37.3 \%)$ \\
\hline \multirow[t]{3}{*}{ Negative Pressure Volume } & $0 \mathrm{cc}$ & $30(18.1 \%)$ \\
\hline & $5 \mathrm{cc}$ & $26(15.7 \%)$ \\
\hline & $10 \mathrm{cc}$ & $110(66.2 \%)$ \\
\hline \multirow[t]{3}{*}{ Needle Size } & 19 gauge & $32(19.3 \%)$ \\
\hline & 22 gauge & $118(71.1 \%)$ \\
\hline & 25 gauge & $16(9.6 \%)$ \\
\hline \multirow[t]{4}{*}{ No. Passes Used } & One & $12(7.2 \%)$ \\
\hline & Two & $78(47 \%)$ \\
\hline & Three & $46(27.7 \%)$ \\
\hline & Four & $24(14.5 \%)$ \\
\hline \multirow[t]{5}{*}{ FNA target site (n) } & Pancreatic lesions & $80(48.1 \%)$ \\
\hline & Gastric lesions. & $34(20.4 \%)$ \\
\hline & Abdominal and mediastinal LNs. & $32(19.2 \%)$ \\
\hline & Hepatobiliary lesions. & $18(10.8 \%)$ \\
\hline & Others. & $2(1.2 \%)$ \\
\hline
\end{tabular}

Table 3. Results of elastography, EUS, FNAC and gold standard method.

\begin{tabular}{|c|c|c|c|c|c|c|c|c|c|c|c|c|c|}
\hline \multirow{3}{*}{ Lesion } & \multicolumn{2}{|c|}{ Elastography } & \multicolumn{3}{|c|}{ EUS } & \multicolumn{4}{|c|}{ Cytology } & \multicolumn{4}{|c|}{ Gold standard } \\
\hline & \multirow{2}{*}{ Positive } & \multirow{2}{*}{ Negative } & \multirow{2}{*}{ Positive } & \multirow{2}{*}{ Negative } & \multirow{2}{*}{ Suspicious } & \multirow{2}{*}{$\begin{array}{l}\text { Positive for } \\
\text { malignancy }\end{array}$} & \multirow{2}{*}{$\begin{array}{c}\text { Negative } \\
\text { for } \\
\text { malignancy }\end{array}$} & \multirow{2}{*}{$\begin{array}{l}\text { Suspicious } \\
\text { for } \\
\text { Malignancy }\end{array}$} & \multirow{2}{*}{ Unsatisfactory } & \multicolumn{2}{|c|}{ Follow up } & \multicolumn{2}{|c|}{ Biopsy } \\
\hline & & & & & & & & & & Positive & Negative & Positive & Negative \\
\hline $\begin{array}{l}\text { Pancreatic } \\
\text { lesions }\end{array}$ & 40 & 40 & 38 & 28 & 14 & 28 & 38 & 10 & 4 & 22 & 32 & 22 & 4 \\
\hline Gastric lesions & 22 & 12 & 32 & 2 & --- & 24 & 2 & --- & 6 & 4 & 6 & 24 & --- \\
\hline $\begin{array}{c}\text { Abdominal/ } \\
\text { mediastinal } \\
\text { LN }\end{array}$ & 16 & 14 & 10 & 4 & 16 & 14 & 14 & --- & 2 & 6 & 10 & 16 & --- \\
\hline Hepatobiliary & 14 & 4 & 12 & 6 & --- & 6 & 8 & --- & --- & 6 & 8 & 4 & --- \\
\hline Others & --- & 2 & --- & --- & 2 & & & & & --- & 2 & --- & --- \\
\hline
\end{tabular}




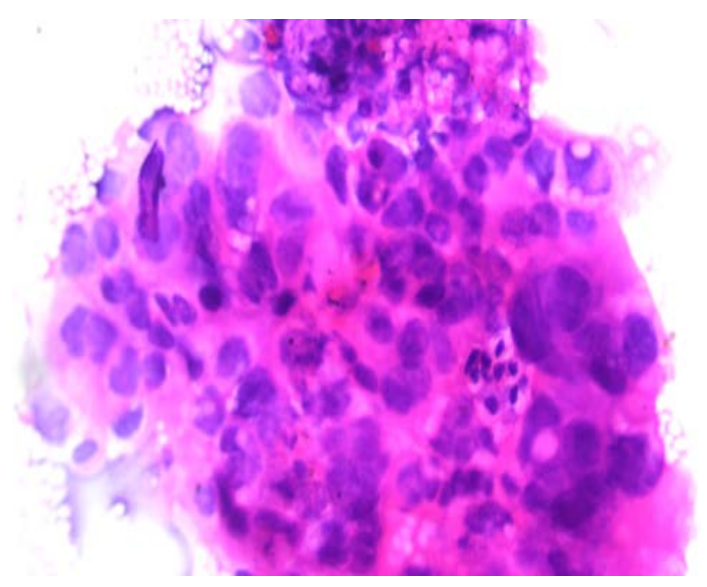

(a)

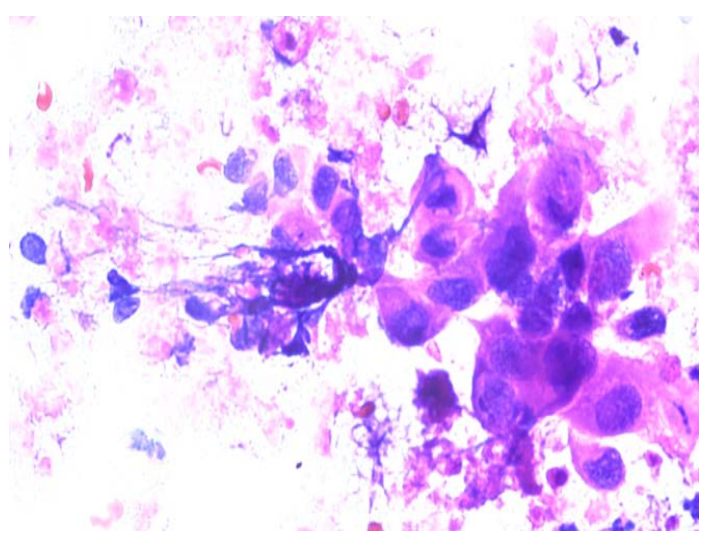

(b)

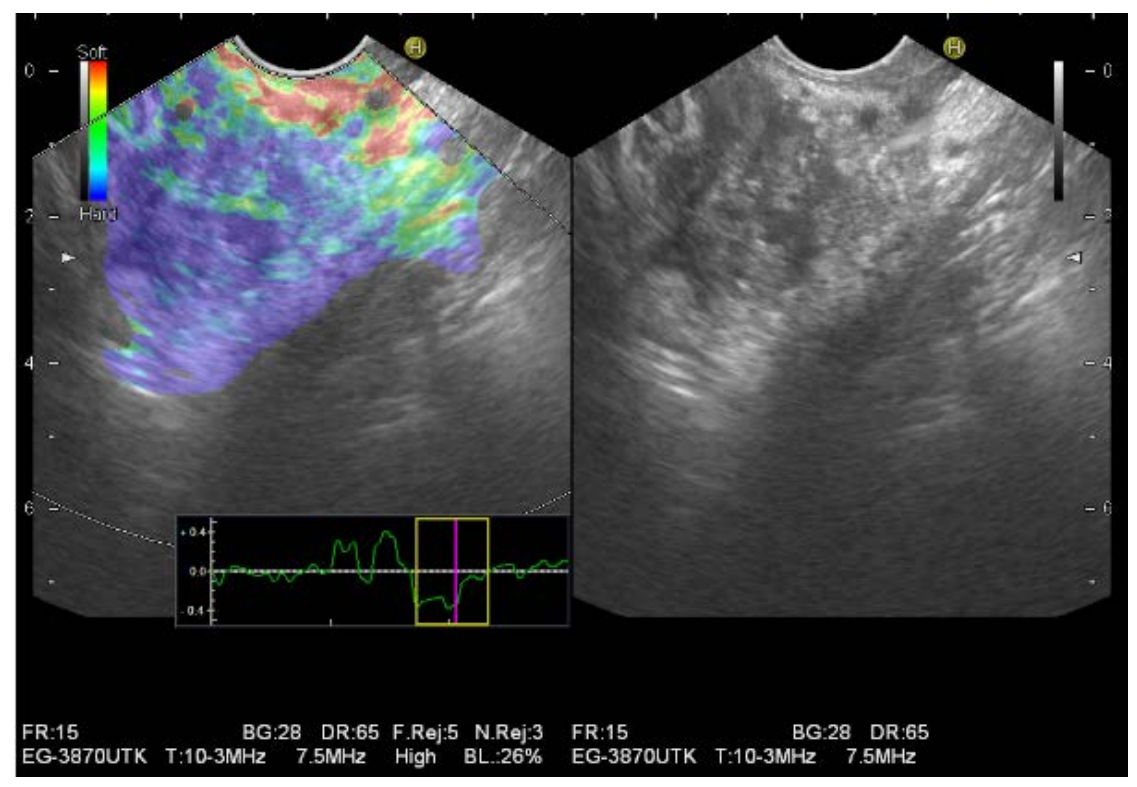

(c)

Figure 1. Ductal adenocarcinoma, high grade. (a) (b) H \& E stain $\times 400$ magnification, smears with overt features of malignancy showed marked nuclear pleomorphism, hyperchromasia, irregular nuclear membranes, nuclear inclusions and single dispersed intact malignant cells; (c) Abdominal ultrasound (right) and elastography (left), malignant featuring pancreatic mass with score 3 elastography. 


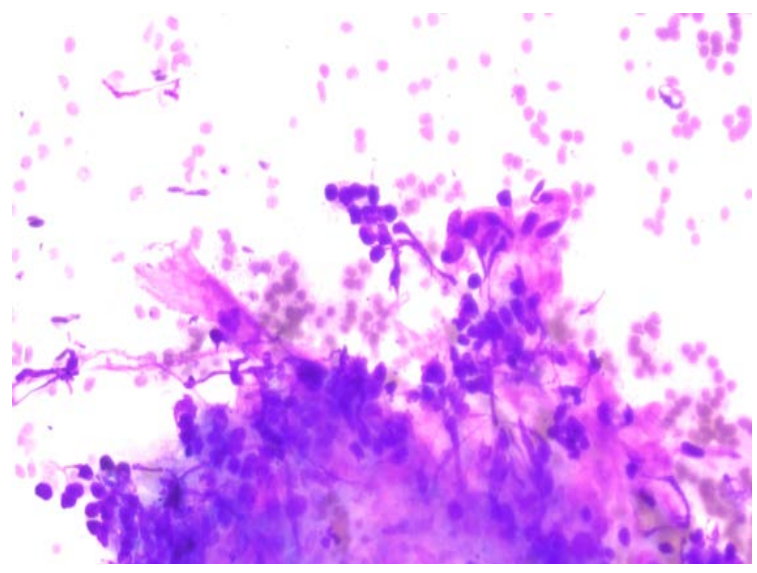

(a)

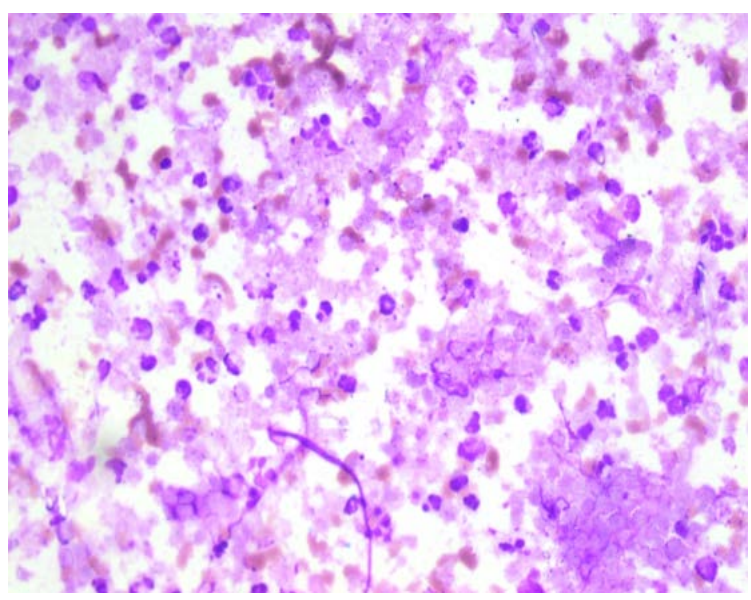

(b)

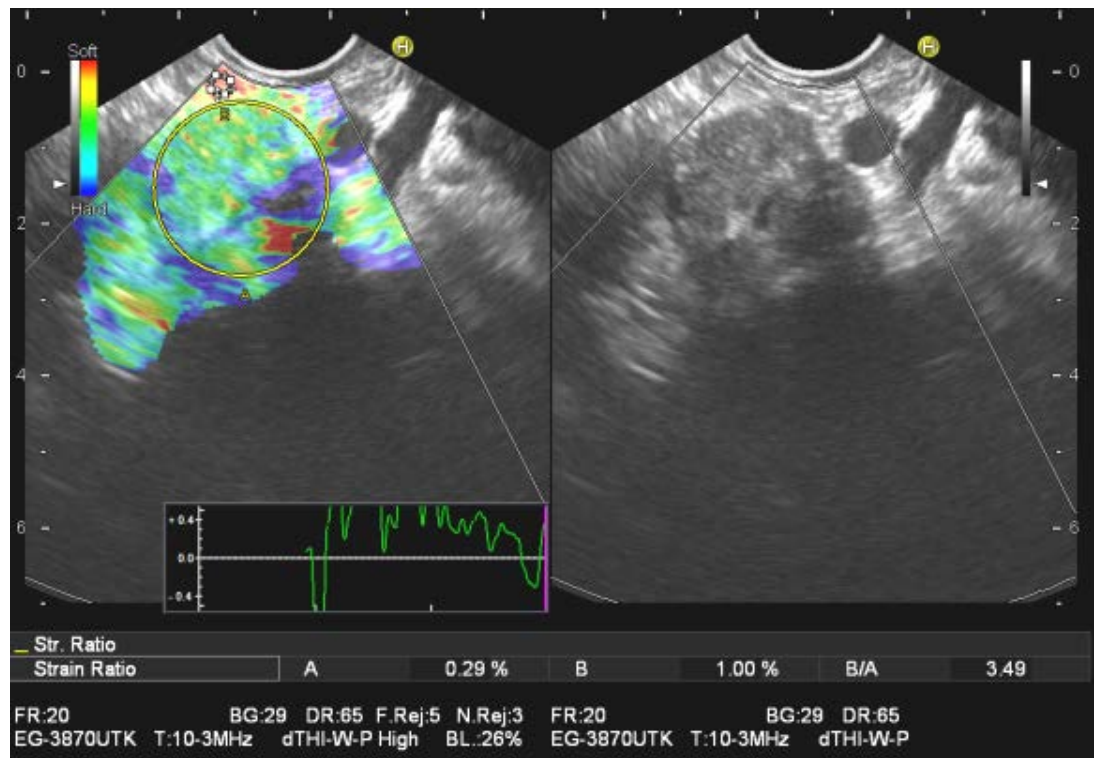

(c)

Figure 2. Chronic pancreatitis. (a) (b) DQ stain $\times 400$ magnification. Acute and chronic inflammation with granular necrotic debris admixed with atrophic pancreatic acini; (c), Abdominal ultrasound (right) and elastography (left), imaging of pancreatic mass that has features of pancreatitis and score 2 elastography. 


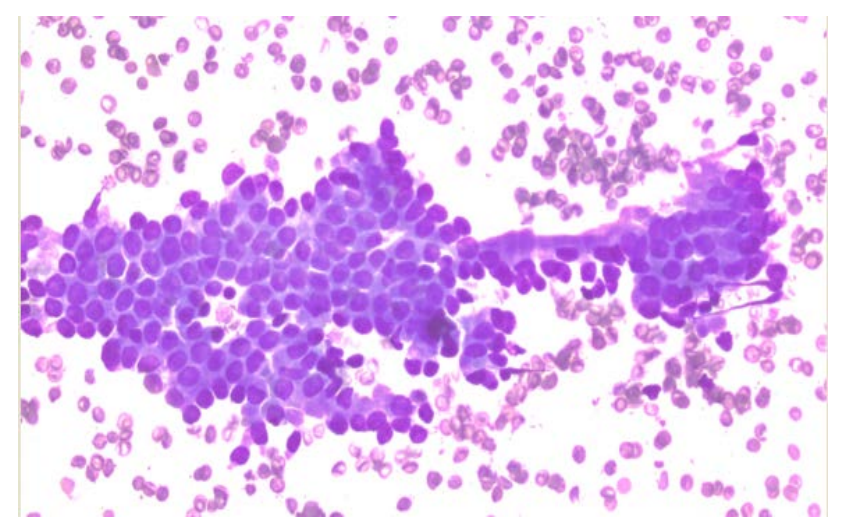

(a)

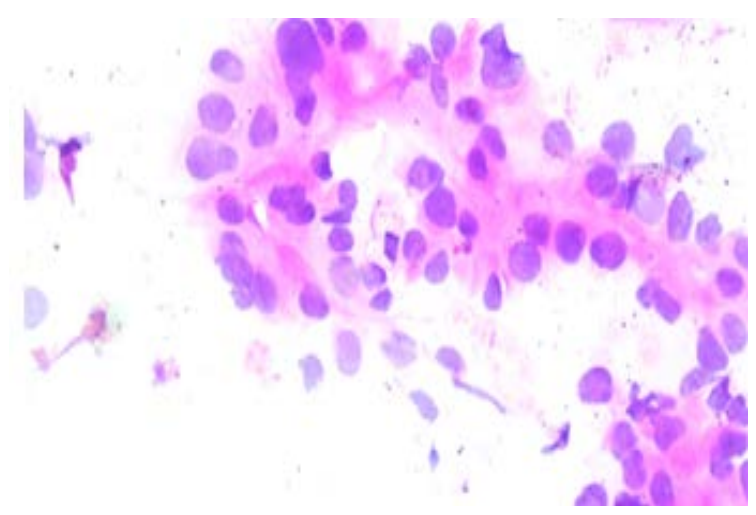

(b)

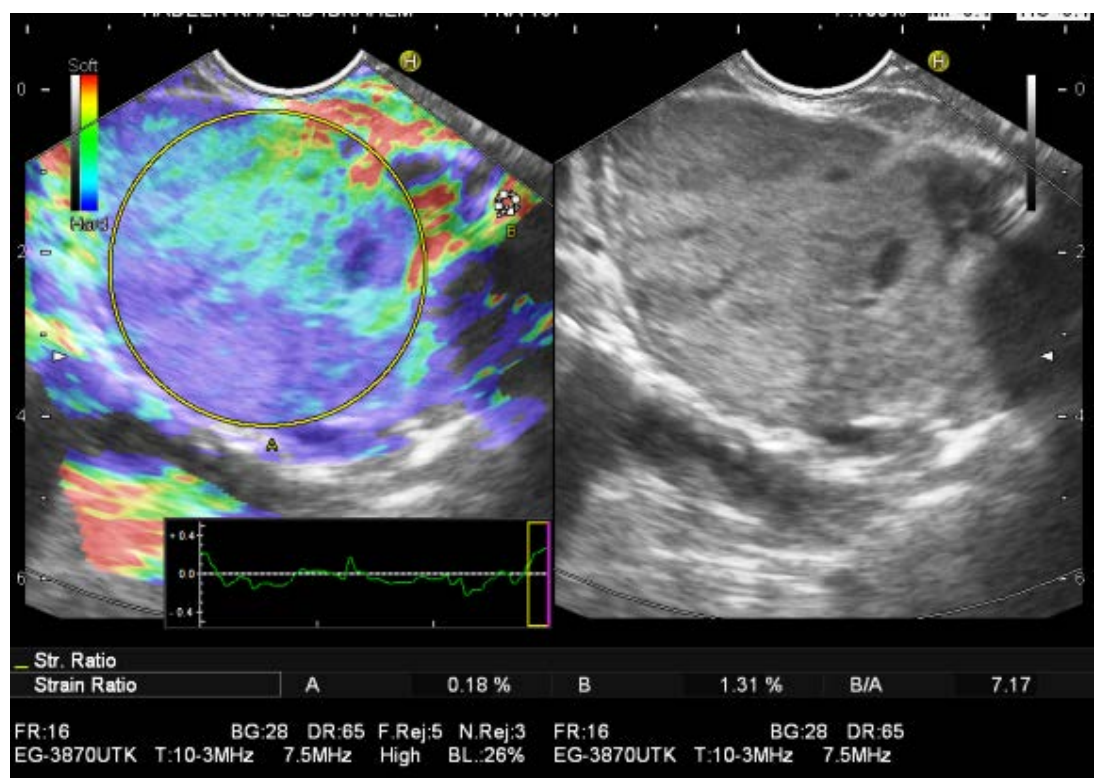

(c)

Figure 3. Solid-pseudopapillary neoplasm of pancrease. (a) DQ stain $\times 200$ magnification; (b) H \& E stain $\times 400$ magnification. Smears revealed cells with small round to oval, occasionally grooved nuclei with finely granular even chromatin and inconspicuous nucleolus with scant granular cytoplasm. Tumor cells surround a vascular core with myxoid change; (c) Abdominal ultrasound (right) and elastography (left), imaging of solid-pseudopapillary neoplasm of pancrease that showed hypoechoic well delineated mass with cystic degeneration and score 3 elastography. 


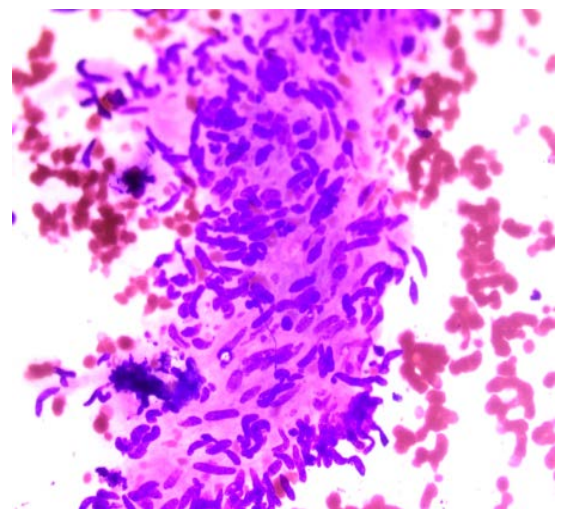

(a)

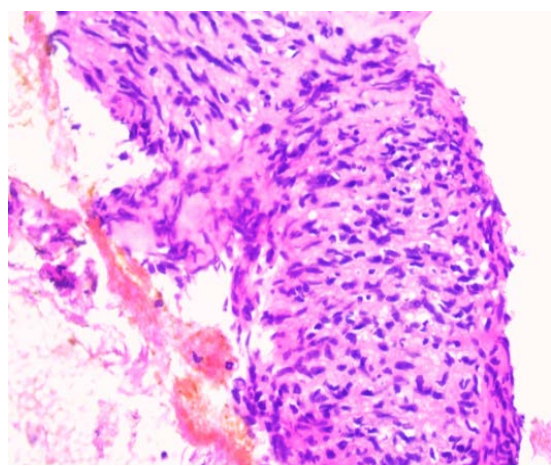

(b)

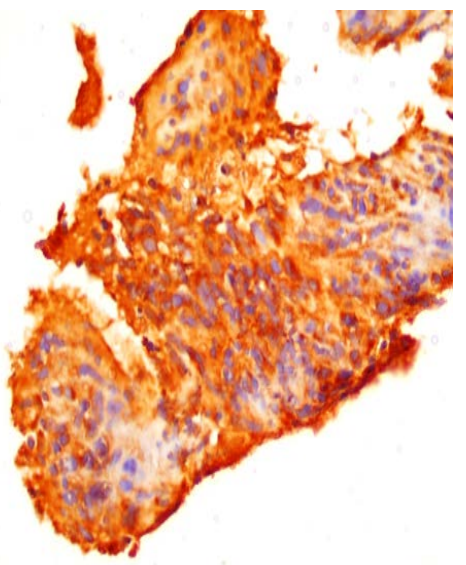

(c)

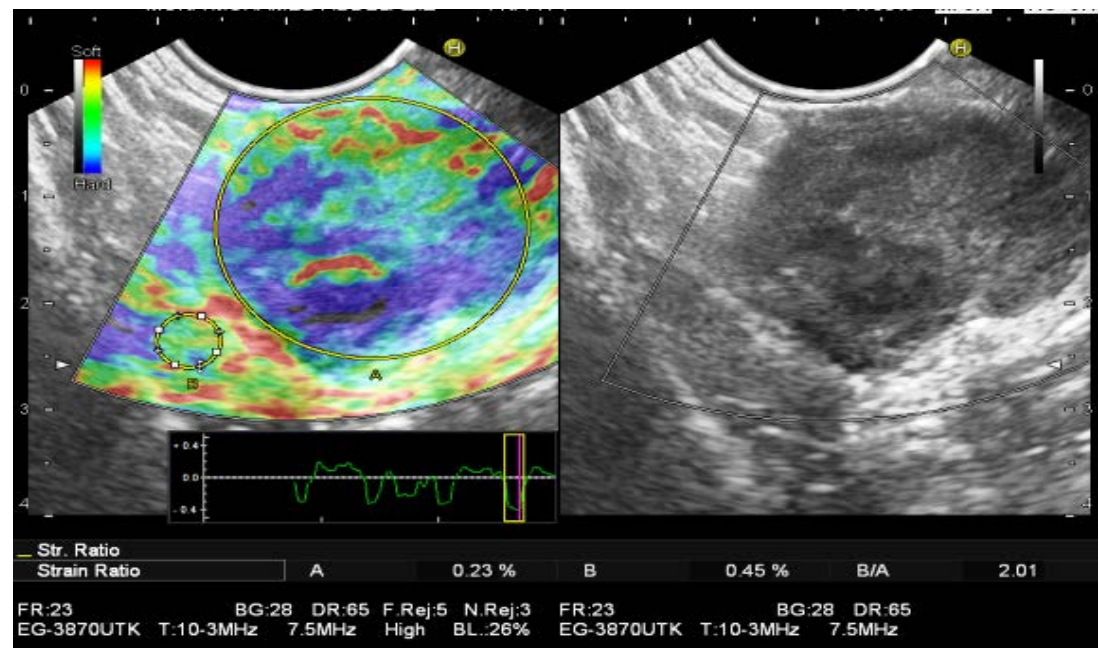

(d)

Figure 4. Gastrointestinal stromal tumor of stomach. (a) DQ stain $\times 400$ magnification, smears formed of tumor cells that are well organized in one direction and showed focally palisading with ill-defined cytoplasmic borders; (b) H \& E stain $\times 200$ magnification, cell block preparation showed tissue fragment formed of groups of tumour cell with spindled nuclei; (c) $\times 400$ power, immunostaining with $\mathrm{CD} 117$, diffuse positive cytoplasmic immunoreactivity; (d) Abdominal ultrasound (right) and elastography (left)) imaging of gastrointestinal stromal tumour of stomach that arises from $4^{\text {th }}$ layer with score 3 elastography. 


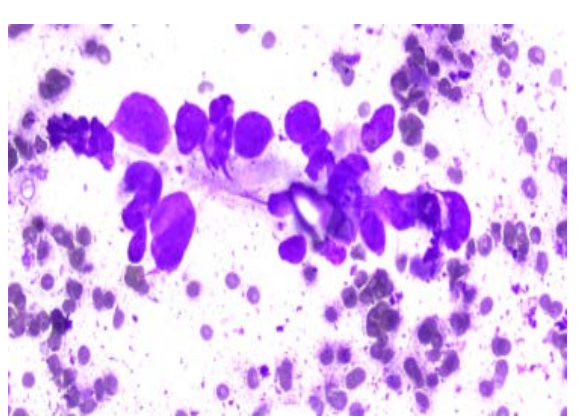

(a)

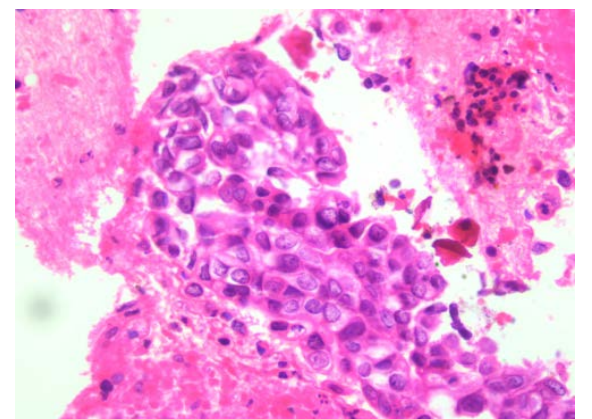

(b)

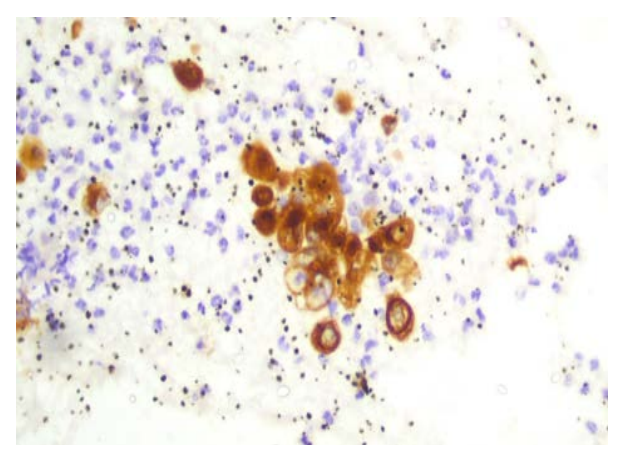

(c)

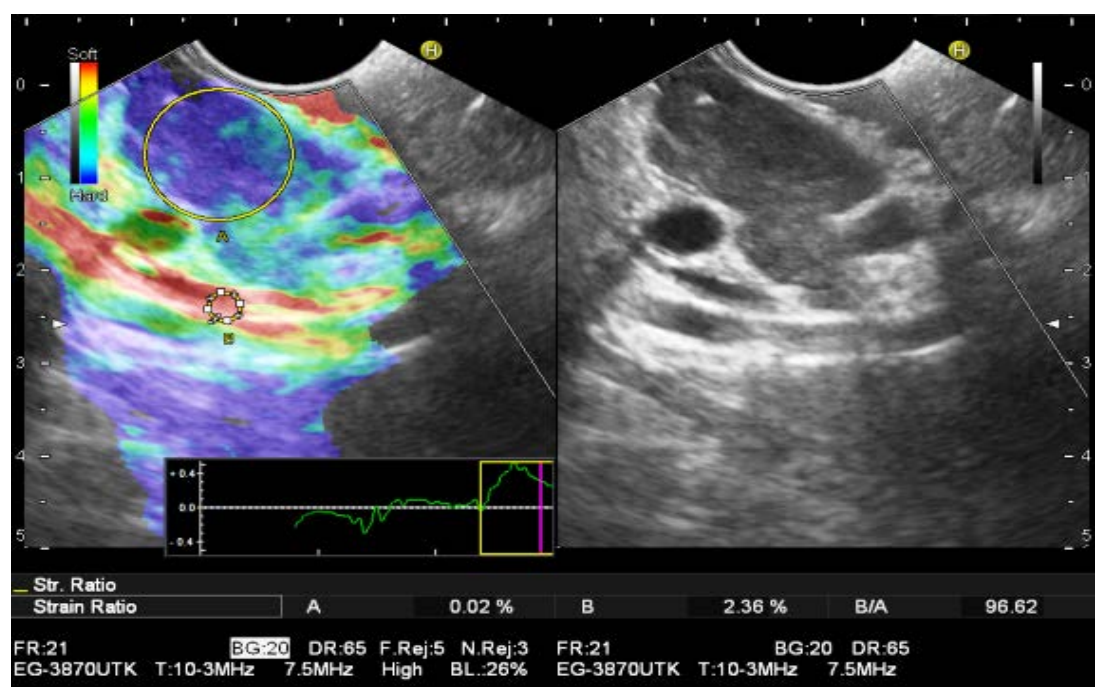

(d)

Figure 5. Metastatic carcinoma of lymph node. (a) DQ stain $\times 400$ magnification, smears revealed groups and aggregates of malignant cells with anisonucleosis, round nucleus and prominent nucleoli; (b) H \& E stain $\times 400$ magnification, cell block preparation showed tissue fragment formed of groups and sheets of malignant epithelial; (c) $\times 400$ power, immunostaining with $\mathrm{CK}$, positive cytoplasmic immunoreactivity in tumour cells; (d) Abdominal ultrasound (right) and elastography (left) imaging of malignant featuring lymph node showed loss of normal regular round contour, elongation and hypoechoic appearance with score 5 elastography.

True positive, true negative, false positive, false negative results and the validity of EUS, elastography and EUS-FNAC in diagnosing gastrointestinal tract lesions and related organs are shown in Table 4. 
Table 4. Positive and negative diagnostic results and the strength of each procedure used in diagnose.

\begin{tabular}{cccccccccc}
\hline $\begin{array}{c}\text { Procedure used } \\
\text { for diagnosis }\end{array}$ & Sensitivity & Specificity & $\begin{array}{c}\text { Positive } \\
\text { predictive value }\end{array}$ & $\begin{array}{c}\text { Negative } \\
\text { predictive value }\end{array}$ & $\begin{array}{c}\text { Diagnostic } \\
\text { accuracy }\end{array}$ & $\begin{array}{c}\text { True } \\
\text { positive }\end{array}$ & $\begin{array}{c}\text { True } \\
\text { negative }\end{array}$ & $\begin{array}{c}\text { False } \\
\text { positive }\end{array}$ & $\begin{array}{c}\text { False } \\
\text { negative }\end{array}$ \\
\hline Cytological diagnosis & $78.8 \%$ & $96.8 \%$ & $97.6 \%$ & $73.2 \%$ & $85.5 \%$ & $53.1 \%$ & $36.1 \%$ & $0 \%$ & $10.8 \%$ \\
EUS diagnosis & $80.4 \%$ & $51.6 \%$ & $75.8 \%$ & $76.2 \%$ & $75.9 \%$ & $57.8 \%$ & $21.6 \%$ & $16.8 \%$ & $3.6 \%$ \\
Elastography diagnosis & $78.8 \%$ & $61.3 \%$ & $77.4 \%$ & $63.3 \%$ & $72.3 \%$ & $49.4 \%$ & $25.3 \%$ & $12 \%$ & $13.3 \%$ \\
\hline
\end{tabular}

Assessment of specimen adequacy at time of EUS procedure was done by ROSE of aspirated sample in $86(51.8 \%)$ samples and was not done in $80(48.2 \%)$ samples.

Between one to four passes were performed for each lesion. The group on whom ROSE was performed, relationship between cytological adequacy and number of passes performed to obtain cytological material from target lesion was done and revealed that $28(32.5 \%)$ cases showed cytological adequacy after $1^{\text {st }}$ pass, $38(44.1 \%)$ cases showed cytological adequacy after $2^{\text {nd }}$ pass, $14(16.2 \%)$ cases showed cytological adequacy after $3^{\text {rd }}$ pass and $4(4.6 \%)$ cases showed cytological adequacy after $4^{\text {th }}$ pass. Among cases for which cell block was performed, they showed cellular adequacy for diagnosis in 48 (88.9\%) cases but was inadequate in $6(11.2 \%)$ cases.

Statistical significant association between elastography, EUS, EUS-FNAC and final diagnostic results (Gold standard) in evaluation of gastrointestinal tract lesions and related organs were detected $(P<0.001)$.

There was statistical significant association between adequate cytological diagnosis and cell block preparations $(P=0.021)$, lesion size $(P=0.019)$, ROSE $(P$ $=0.031)$ and number of passes from sampled lesions $(P=0.030)$.

Cytological sufficiency was detected at mean lesion size $5.55 \pm 3.9 \mathrm{~cm}$ while cytological insufficiency was seen at mean lesion size $2.49 \pm 1.5 \mathrm{~cm}$.

Adequate cytological sufficiency was detected in 78 (57.4\%) cases when ROSE was present.

In the presence of ROSE cytological sufficiency was seen at $1^{\text {st }}$ pass used to obtain material by EUS guided FNAC in $28(35.9 \%)$ cases, at $2^{\text {nd }}$ pass in 32 $(41.1 \%)$ cases, at $3^{\text {rd }}$ pass in $14(17.9 \%)$ cases and at $4^{\text {th }}$ pass in $4(5.1 \%)$ cases

There was no statistical significant association between satisfactory cytological diagnosis and lesion Site $(P=0.247)$, approach used to obtain cytological specimen $(P=0.244)$, number of fanning of needle within lesion $(P=0.093)$, needle size used $(P=0.065)$, volume of negative suction pressure used $(P=0.171)$ and number of passes used $(P=0.0 .772)$.

\section{Discussion}

EUS guided FNAC has integrated into the diagnostic and staging algorithm for evaluation of benign and malignant submucosal lesions of the gastrointestinal tract and adjacent organs [14].

Our results agreed with previously performed studies who reported improved 
diagnostic accuracy of EUS when combined with FNAC and established the harmonizing role of EUS when added to EUS [5] [19] [20]. LV et al. (2019) showed similar results to our study and confirmed the complementary role of EUS-FNAC in upgrading diagnostic accuracy of elastography [7]. Our study agreed with work performed by Haba S. et al. (2013) that reported improvement of diagnostic accuracy of EUS-FNAC when cell-block preparation was performed that gives opportunity for immunohistochemical studies [21].

The overall high values of sensitivity, specificity and diagnostic accuracy noticed in our work agreed with same ranges detected in study performed by Siddiqui et al. (2011) with $84 \%$ sensitivity, $86 \%$ specificity and $86 \%$ diagnostic accuracy. Similarly, Bor et al. (2019) reported same ranges of sensitivity, specificity and diagnostic accuracy with values of $83.1 \%, 100 \%$ and $78.3 \%$ respectively [5] [20].

In contrast, Larghi et al. (2011), Kim et al. (2014) and Sugiura et al. (2019) showed higher values with $100 \%$ specificity and positive predictive value and more than $90 \%$ sensitivity and negative predictive value of EUS-FNAC [4] [22] [23]. This discrepancy can be explained by small sample size of single center study in our work. Moreover, ROSE was not performed for all cases with obvious effect on cytology adequacy and number of unsatisfactory cytological results. In addition, the difference in patient demographics in our study group in comparison with previously conducted studies affects outcomes values.

In the preset study significant association was detected between cytological diagnostic adequacy with cell block preparations, lesion size, ROSE and number of passes. Haba S. et al. (2013) agreed with our work that showed significant association of lesion size, availability of on-site cytopathologic evaluation and cell-block preparations with accuracy of EUS-FNA cytological diagnosis [21]. Sugiura et al. (2019) also agreed with our results and demonstrated that mass size and ROSE are significantly associated with reduction needle pass numbers and cytological diagnostic accuracy while needle bore size did not improve cytological diagnostic yield [4]. In agreement with the present study, Yoganand V. Patil et al. (2016) who demonstrated statistical significant association of availability of ROSE and number of passes with cytological diagnosis [24]. Moreover, Iglesias-Garcia et al. (2015) agreed with our work and reported significance association of diagnostic accuracy of EUS-FNAC with ROSE at the time of procedure [25] while Raddaoui et al. (2015) showed significant association with adequate cell block preparation [26].

On the other hand, Bor et al. (2019) showed controversy results and illustrated that using standard suction technique showed significant association with cytological sufficiency. They also showed the significance of capillary suction (Slow pull suction) that should be performed for first passes and then followed by standard suction for subsequent passes in absence of ROSE [5]. Also, disagreement results showed by Inoue et al., 2016 that lesion size was the only factor showing significance association with cytological adequacy and correct diagnosis 
[27]. This argument on optimal factors that affect cytological adequacy and inconsequence cytological diagnosis between our results and previous studies is related to several factors. First of all, our study was single center study. Second, ROSE was not performed for all cases. Third, the study was performed on small number of patients.

\section{Conclusion}

EUS, EUS-FNAC and elastography should be integrated together for accurate diagnosis of gastrointestinal submucosal lesions and related organs. Addition of EUS-FNAC to EUS and elastography increases and improves diagnostic accuracy of lesions and minimizes rates of false negative and false positive results. We determine that elastography not only used to predict the nature of lesion, but also to identify the most proper site of sampling from target lesion. We also conclude that maximal cytological sufficiency can be achieved by adequate cell block preparations, larger lesion size, performance of ROSE and using at least two passes from target lesion. We recommend performance of ROSE for all cases and particularly for lesions equal to or less than $2 \mathrm{~cm}$.

\section{Acknowledgements}

This paper is part of MD thesis. It is approved by ethical approval of institutional review board of South Egypt Cancer Institute at Assiut University and funded by research unit of South Egypt Cancer Institute at Assiut University with grant number and RIB Number: 392. All authors have no conflict of interest regarding publishing this paper.

\section{Conflicts of Interest}

The authors declare no conflicts of interest regarding the publication of this paper.

\section{References}

[1] Fujimori, N., et al. (2016) Efficacy of Endoscopic Ultrasonography and Endoscopic Ultrasonography-Guided Fine-Needle Aspiration for the Diagnosis and Grading of Pancreatic Neuroendocrine Tumors. Scandinavian Journal of Gastroenterology, 51, 245-252. https://doi.org/10.3109/00365521.2015.1083050

[2] Sugimoto, M., et al. (2015) Conventional versus Contrast-Enhanced Harmonic Endoscopic Ultrasonography-Guided Fine-Needle Aspiration for Diagnosis of Solid Pancreatic Lesions: A Prospective Randomized Trial. Pancreatology, 15, 538-541. https://doi.org/10.1016/j.pan.2015.06.005

[3] Polkowski, M., et al. (2017) Technical Aspects of Endoscopic Ultrasound (EUS)-Guided Sampling in Gastroenterology: European Society of Gastrointestinal Endoscopy (ESGE) Technical Guideline-March 2017. Endoscopy, 49, 989-1006. https://doi.org/10.1055/s-0043-119219

[4] Sugiura, R., et al. (2019) Effect of Pancreatic Mass Size on Clinical Outcomes of Endoscopic Ultrasound-Guided Fine-Needle Aspiration. Digestive Diseases and Sciences, 64, 2006-2013. https://doi.org/10.1007/s10620-018-5435-3 
[5] Bor, R., et al. (2019) Prospective Comparison of Slow-Pull and Standard Suction Techniques of Endoscopic Ultrasound-Guided Fine Needle Aspiration in the Diagnosis of Solid Pancreatic Cancer. BMC Gastroenterology, 19, 6. https://doi.org/10.1186/s12876-018-0921-9

[6] Wang, J., et al. (2018) Role of Endoscopic Ultrasound-Guided Fine-Needle Aspiration in Evaluating Mediastinal and Intra-Abdominal Lymphadenopathies of Unknown Origin. Oncology Letters, 15, 6991-6999. https://doi.org/10.3892/ol.2018.8253

[7] Lv, H., Zhu, G. and Zhou, L. (2019) Diagnostic Value of Endoscopic Ultrasound Elastography for Benign and Malignant Digestive System Tumors. Pakistan Journal of Medical Sciences, 35, 1461-1465. https://doi.org/10.12669/pjms.35.5.1075

[8] Dietrich, C.F., Saftoiu, A. and Jenssen, C. (2014) Real Time Elastography Endoscopic Ultrasound (RTE-EUS), a Comprehensive Review. European Journal of Radiology, 83, 405-414. https://doi.org/10.1016/j.ejrad.2013.03.023

[9] Cui, X.-W., et al. (2015) Endoscopic Ultrasound Elastography: Current Status and Future Perspectives. World Journal of Gastroenterology, 21, 13212-13224. https://doi.org/10.3748/wjg.v21.i47.13212

[10] Mukai, S., et al. (2016) Multicenter, Prospective, Crossover Trial Comparing the Door-Knocking Method with the Conventional Method for EUS-FNA of Solid Pancreatic Masses (with Videos). Gastrointestinal Endoscopy, 83, 1210-1217. https://doi.org/10.1016/j.gie.2015.10.025

[11] Lopes, C.V., Hartmann, A.A. and Artifon, E.L.A. (2018) EUS-FNA with 19 or 22 Gauges Needles for Gastric Subepithelial Lesions of the Muscle Layer. Arquivos brasileiros de cirurgia digestiva: ABCD, 31, e1350-e1350. https://doi.org/10.1590/0102-672020180001e1350

[12] Klapman, J.B., Logrono, R., Dye, C.E. and Waxman, I. (2003) Clinical Impact of on-Site Cytopathology Interpretation on Endoscopic Ultrasound-Guided Fine Needle Aspiration. The American Journal of Gastroenterology, 98, 1289-1294.

[13] Balekuduru, A.B., et al. (2017) Comparison of Diagnostic Yield of Endoscopic U1trasound-Guided Fine-Needle Aspiration Cytology and Cell Block in Solid Lesions. Journal of Digestive Endoscopy, 8, 176-181. https://doi.org/10.4103/jde.JDE_53_17

[14] Inoue, T., et al. (2018) Impact of Endoscopic Ultrasound-Guided Fine-Needle Biopsy on the Diagnosis of Subepithelial Tumors: A Propensity Score-Matching Analysis. Digestive Endoscopy, 31, 156-163. https://doi.org/10.1111/den.13269

[15] William Brugge, J.D., Klapman, J.B., Ashfaq, R., Shidham, V., Chhieng, D., Kwon, R., Baloch, Z., Zarka, M. and Staerkel, G. (2014) Techniques for Cytologic Sampling of Pancreatic and Bile Duct Lesions. Diagnostic Cytopathology, 42, 333-337. https://doi.org/10.1002/dc.23096

[16] Chin, Y.K., et al. (2017) Accuracy of Endoscopic Ultrasound-Guided Tissue Acquisition in the Evaluation of Lymph Nodes Enlargement in the Absence of on-Site Pathologist. World Journal of Gastroenterology, 23, 5755-5763. https://doi.org/10.3748/wjg.v23.i31.5755

[17] Tsutsumi, H., et al. (2015) Clinical Impact of Preoperative Endoscopic Ultrasound-Guided Fine-Needle Aspiration for Pancreatic Ductal Adenocarcinoma. Endoscopic Ultrasound, 5, 94-100. https://doi.org/10.4103/2303-9027.180472

[18] Wang, J., et al. (2016) Comparing Endoscopic Ultrasound (EUS)-Guided Fine Needle Aspiration (FNA) versus Fine Needle Biopsy (FNB) in the Diagnosis of Solid Lesions: Study Protocol for a Randomized Controlled Trial. Trials, 17, 198. https://doi.org/10.1186/s13063-016-1316-2 
[19] Okasha, H., et al. (2017) Endoscopic Ultrasound-Guided Fine-Needle Aspiration and Cytology for Differentiating Benign from Malignant Lymph Nodes. Arab Journal of Gastroenterology, 18, 74-79. https://doi.org/10.1016/j.ajg.2017.05.015

[20] Siddiqui, A.A., et al. (2011) Relationship of Pancreatic Mass Size and Diagnostic Yield of Endoscopic Ultrasound-Guided Fine Needle Aspiration. Digestive Diseases and Sciences, 56, 3370-3375. https://doi.org/10.1007/s10620-011-1782-Z

[21] Haba, S., et al. (2013) Diagnostic Ability and Factors Affecting Accuracy of Endoscopic Ultrasound-Guided Fine Needle Aspiration for Pancreatic Solid Lesions: Japanese Large Single Center Experience. Journal of Gastroenterology, 48, 973-981. https://doi.org/10.1007/s00535-012-0695-8

[22] Larghi, A., et al. (2011) EUS-Guided Fine-Needle Tissue Acquisition by Using a 19-Gauge Needle in a Selected Patient Population: A Prospective Study. Gastrointestinal Endoscopy, 74, 504-510. https://doi.org/10.1016/j.gie.2011.05.014

[23] Kim, G.H., et al. (2014) Comparison of 22-Gauge Aspiration Needle with 22-Gauge Biopsy Needle in Endoscopic Ultrasonography-Guided Subepithelial Tumor Sampling. Scandinavian Journal of Gastroenterology, 49, 347-354. https://doi.org/10.3109/00365521.2013.867361

[24] Patil, Y.V., et al. (2016) Profile of Endoscopic Ultrasound Guided Fine-Needle Aspiration Cytology (EUS-FNAC) in the Gastrointestinal and Peri-Intestinal Lesions. International Journal of Contemporary Medical Research, 3, 1747-1749.

[25] Iglesias-Garcia, J., Lariño-Noia, J., Lindkvist, B. and Domínguez-Muñoz, J.E. (2015) Endoscopic Ultrasound in the Diagnosis of Chronic Pancreatitis. Revista espanola de enfermedades digestivas. organo oficial de la Sociedad Espanola de Patologia Digestiva, 107, 221-228.

[26] Raddaoui, E., Almadi, M.A., Aljebreen, A.M. and Alsaif, F. (2015) Cytologic diagnosis of gastric submucosal lesions by endoscopic ultrasound-guided fine-needle aspiration: A single center experience in Saudi Arabia. Indian Journal of Pathology and Microbiology, 58, 448-452. https://doi.org/10.4103/0377-4929.168868

[27] Inoue, T., et al. (2016) Assessment of Factors Affecting the Usefulness and Diagnostic Yield of Core Biopsy Needles with a Side Hole in Endoscopic Ultrasound-Guided Fine-Needle Aspiration. Gut Liver, 10, 51-57.

https://doi.org/10.5009/gnl14249 